\title{
Progress in design of adsorption refrigeration systems. Evaporators
}

\author{
Wojciech Kalawa ${ }^{1 *}$, Karolina Grabowska ${ }^{2}$, Karol Sztekler ${ }^{1}$,Jarosław Krzywański ${ }^{2}$, Marcin Sosnowski ${ }^{2}$, Sebastian \\ Stefański ${ }^{1}$, Tomasz Siwek ${ }^{1}$ and Wojciech Nowak $^{1}$ \\ ${ }^{1}$ AGH University of Science and Technology, A. Mickiewicza Av. 30, 30-059 Krakow, Poland \\ ${ }^{2}$ Jan Dlugosz University, Armii Krajowej Av. 13/15, 42-200 Czestochowa, Poland
}

\begin{abstract}
Adsorption heat pumps are becoming increasingly popular. Due to their design, they enable application of low-temperature heat sources. Evaporators for adsorption chillers make one of the basic design elements determining the correct operation of these devices. The specificity of operation in low pressures and temperatures is the reason why their design significantly differs from that of conventional evaporators. The pluralities of existing solutions as well as the lack of a systematic review of them cause difficulties in correct evaluation and choice of design. The paper presents the current state of art as well as a review of the existing solutions of evaporators used in adsorption heat pumps. The purpose of the review research is to present various solutions of evaporators as well as indicating their advantages and disadvantages in order facilitate the choice of the optimal design.
\end{abstract}

\section{Introduction}

Evaporators for adsorption refrigeration appliances operate at low pressure and temperature regimes. Their typical operating parameters are within the ranges of 3$20^{\circ} \mathrm{C}$ and $0.76-2.34 \mathrm{kPa}[1]$. The design of low-pressure adsorption evaporators in refrigeration systems differs considerably from the typical shell and tube heat exchangers, which can be used as surface condenser due to the fact that condensate is collected in their outlet section [2]. As for an evaporator, for such low pressures that occur in adsorption heat pumps $(\sim 1 \mathrm{kPa})$, the liquid accumulated there forms a liquid column which causes an increase in the saturation temperature in the lower, submerged area of the evaporator, leading to a drop in the cooling capacity of the adsorption heat pump [1-4].

The literature of the subject distinguishes three basic types of evaporators $[3,5,6]$ :

- flooded;

- capillary assisted;

- falling film.

According to the literature, the latter two designs allow for reducing the most essential disadvantage of flooded evaporators, which is the above-mentioned adverse effect of the hydrostatic pressure of the water column on the functioning of low-pressure evaporators $[1,2]$. Heat flow resistance, both within the chilled water flowing inside the tube bundles and on the outside of it, on the side of the cooling agent, represents an essential contribution to the total heat transfer resistance. The resistance to heat transfer from chilled water to the external surface of the tube wall and from the external surface of the tube to the ambient medium for smooth tubes is comparable and equal to $51 \%$ and $48.8 \%$, respectively, of the total heat flow resistance $[1,7]$. Taking account of the well-known principle of the theory of heat transfer according to which heat transfer enhancement takes place most effectively while reducing the greatest partial resistance, attention should be focussed on reducing these two components of the total heat transfer resistance $[8,9]$. One of the solutions that enable a reduction of heat resistance on the internal part of the tube bundle is by introducing special systems, socalled turbulators which cause the flow to be more turbulent and thereby enhance heat transfer [2,4,10,11]. Two basic designs of such turbulators are a twisted tape that allows fluid flow through the central part of the tube and a Z-type turbulator. On the other hand, reduction of heat transfer resistance from the external surface of the exchanger to the ambient is possible by modifying the external surface, e.g. applying a porous coating on this surface [3]. Further, the paper contains more detailed characteristics of the methods of enhancing heat transfer within evaporators of adsorption chillers.

\section{Flooded evaporators}

Flooded evaporators are most commonly pipe evaporators, occasionally shell and tube ones with tube bundles immersed in cooling liquid [1,5]. The immersion depth of the bundles is one of the characteristics of this type of evaporators. Research conducted by Thimmaiah et al. [3] demonstrated that the highest cooling capacity was achieved when finned tubes were immersed in the agent to a depth equal to $80 \%$ of the tube diameter. In the research presented in the paper by Volmer et al. [12]

* Corresponding author: kalawa@agh.edu.pl 
it was observed that the value of the heat transfer coefficient was largely affected by the fin pitch, that is to say the distance between the fins. The study comprised tube bundles with fin pitch values of $1.6 \mathrm{~mm}, 3.3 \mathrm{~mm}$, $5.0 \mathrm{~mm}$ and $8.0 \mathrm{~mm}$. As it was established, the heat transfer coefficient decreased along with the decreasing pitch. A small amount of adsorbate was found to be accumulated in the $3.3 \mathrm{~mm}, 5.0 \mathrm{~mm}$ and $8.0 \mathrm{~mm}$ spaces, which reduced the occurrence of capillary action. As it was stressed, the filling of the spaces between the fins with liquid, taking place at low pitches (high fin densities), implies a reduction of the evaporation surface area and consequently a deterioration of the heat exchange conditions. Volmer et al. [12] also observed that an increase in the thickness of the fins leads to improved heat transfer coefficient. In order to reduce the adverse effect of the hydrostatic pressure of the refrigerant column in flooded evaporators and the resulting changes in its saturation pressure and temperature along the diameter of the evaporator tubes (in the direction perpendicular to the axis of the horizontal evaporator tube), new designs of low-pressure evaporators have been created, i.e. capillary-assisted and falling film evaporators.

\section{Capillary assisted evaporators}

These are evaporators with tube bundles with an extended outside surface (e.g. finned), partially immersed and contacting the refrigerant in the tank. As a result of capillary action, the refrigerant column rises (so-called capillary rise) in the tank and causes the outside surface of the tube bundle to be covered uniformly with the liquid (refrigerant or water). The study by Thimmaiah et al. [2] examined five types of finned tubes with different fin geometries and the results were referred to the data obtained for a plain tube (Table 1). The highest heat transfer coefficient was found for the evaporator with the Turbo Chil-40 FPI tubes, with values in the range of $596-888 \mathrm{~W} /\left(\mathrm{m}^{2} \cdot \mathrm{K}\right)$ for chilled water temperatures $10-20^{\circ} \mathrm{C}$ while the values of this coefficient for plain tube wee in the range of 285-365 $\mathrm{W} /\left(\mathrm{m}^{2} \cdot \mathrm{K}\right)$.

Table 1. Geometric parameters of the evaporator tubes investigated by Thimmaiah et al. [2].

\begin{tabular}{|c|c|c|}
\hline Tube type & Fin structure & $5 \mathrm{x}$ zoom view \\
\hline $\begin{array}{l}\text { Turbo Chill -26 FPI } \\
\text { Material: Copper alloys C12200 } \\
\text { Fin type: contin. and parallel fins } \\
\text { Diameter: } 3 / 4 " \\
\text { Fin height } 1.422 \mathrm{~mm} \\
\text { Min. Wall under fins: } 0.737 \mathrm{~mm} \\
\text { Inside surface area: } 0.049 \mathrm{~m}^{2} / \mathrm{m} \\
\text { Outside Surface area: } 0.193 \mathrm{~m}^{2} / \mathrm{m}\end{array}$ & & है. \\
\hline $\begin{array}{l}\text { Turbo Chill -40 FPI } \\
\text { Material: Copper alloys C12200 } \\
\text { Fin type: contin. and parallel fins } \\
\text { Diameter: } 3 / 4 " \\
\text { Fin height: } 1.473 \mathrm{~mm} \\
\text { Min. Wall under fins: } 0.635 \mathrm{~mm} \\
\text { Inside surface area: } 0.051 \mathrm{~m}^{2} / \mathrm{m} \\
\text { Outside Surface area: } 0.263 \mathrm{~m}^{2} / \mathrm{m}\end{array}$ & & f \\
\hline
\end{tabular}

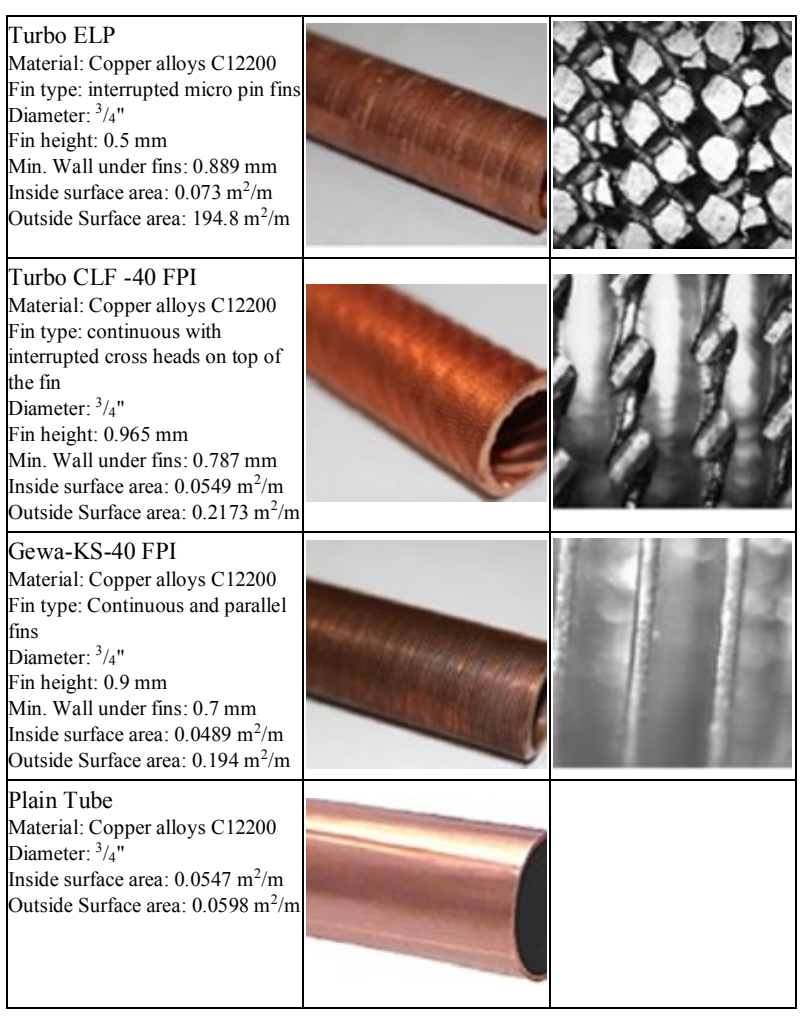

\section{Falling film evaporators}

In falling film evaporators the refrigerant is distributed on the outside surface of the evaporator tubes. This is the basic type of evaporator used in adsorption chillers [4].

The advantages of this type of design include high heat transfer coefficients, low refrigerant charge and reduced leakage risk $[13,14] 14$. Thus, these evaporators allow for reducing the space required for the installation of the device $[14,15]$.

Their main disadvantages include high requirements concerning the proper distribution of the refrigerant liquid over the surface of the tube bundle in the evaporator [13]. With regard to the way of distributing the refrigerant on the surface of the tube bundles, falling film evaporators can be divided into two groups, i.e. a) spraying and b) trickling [14]. The former group of evaporators typically require circulation pumps to deliver the refrigerant liquid to the evaporator in an amount greater than the amount of refrigerant evaporated from the surface of the tubes. Trickling evaporators, on the other hand, require a system of refrigerant distribution ensuring even distribution over the surface of the first upper row in the tube bundle of the evaporator. These do not require installation of circulation pumps. They ensure higher performance levels than spraying evaporators provided that the refrigerant is uniformly distributed over the surface of the evaporator tubes and its mass is precisely dosed in an amount corresponding to the mass of the evaporated refrigerant [14]. Results of various analyses of the configuration of tube bundles in a spraying evaporator have been presented in a study by Yang and Wang [14]. The analysis particularly comprised three different arrangements of the evaporator tubes, i.e. in 
neighbouring rows (aligned next to each other), staggered downwards from the top to the bottom (liquid inlet at the top, outlet at the bottom) and from the bottom to the top. The designs of the arrangements investigated have been shown in Fig. 1.
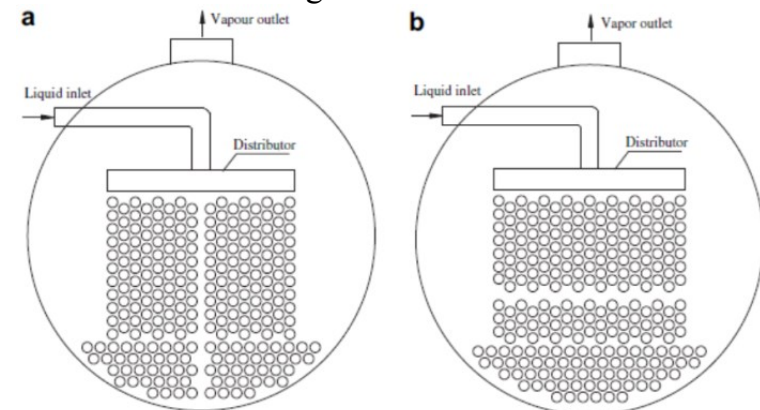

Fig. 1. Tube arrangements in a spray evaporator, investigated in the study by Yang and Wang [14]; a) evaporator tubes arranged in neighbouring rows (aligned next to each other), b) form the bottom to the top.

The investigation revealed that the most advantageous configuration is an evaporator with staggered tube arrangement form the bottom to the top. It was for this solution that the highest heat transfer coefficients were observed, equal to $7.840 \mathrm{~W} /\left(\mathrm{m}^{2} \cdot \mathrm{K}\right)$. The heat transfer coefficient increased along with the increase in the refrigerant liquid flux (elimination of dry surfaces on the evaporator tubes) up to a certain value above which the coefficient remained practically unchanged. Application of a finned tube design (with extended outside and inside surfaces) enabled increasing the heat transfer coefficient by $62.6 \%$. An essential performance indicator of this type of evaporator is the number of tubes flooded. With respect to the most advantageous tube arrangement, from the bottom to the top, the heat flux increased along the increase in the number of tubes covered with the refrigerant. After reaching a certain maximum, however, further increase in this number did not cause any increase in the exchanged heat flux [14]. An investigation of a bundle of 6 horizontally arranged tubes in a falling film evaporator have been presented in a paper by $\mathrm{Li}$ et al. [15]. The analysis comprised Turbo-CAB tubes with a fin density of 19 and 26 FPI (fins per inch) as well as Korodense tubes with wavy inside and outside surfaces (Fig. 2).

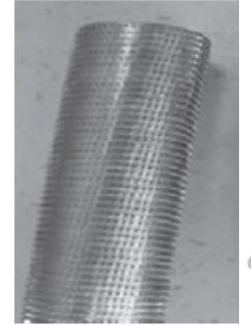

a)

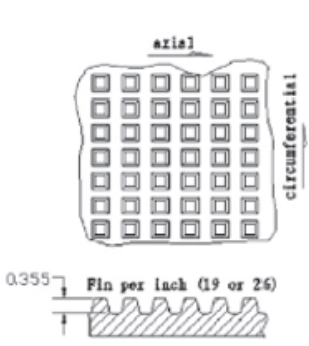

b)

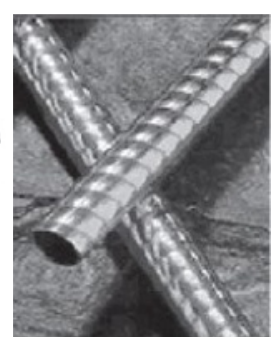

c)
Fig. 2. Characteristics of falling film evaporator investigated by Li et al. [15]; a) Turbo-CAB 19 FPI tube b) Turbo-CAB tube fins, c) Korodense tubes.

The test revealed that together with an increase in Reynolds number, the heat transfer coefficient first increased rapidly and then fell slowly after reaching a maximum. The maximum values of heat transfer coefficients obtained in the tests for these tubes were equal to $4,500 \mathrm{~W} /\left(\mathrm{m}^{2} \cdot \mathrm{K}\right)$.

The increase in the heat transfer coefficient with simultaneous extension of the inside and outside heat exchange surfaces has also been observed in a study by [7]. More details concerning this solution have been discussed in a further part of the paper.

\section{Turbulators and modifications of the heat exchange surface}

The experimentally predicted impact of the flux value of the liquid flowing in evaporator tube bundles on the value of the heat transfer coefficient has been confirmed in many studies $[1,2,12]$. As it has been established, the heat exchange conditions are improved with an increase in the chilled water flow rate. Also, the negligible heat flow resistance was confirmed and two essential heat transfer resistances were indicated, from the liquid, inside the bundle and from the outside surface of the heat exchanger [12].

The methods of enhancing heat exchange are divided into three groups, i.e. a) active, b) passive and c) complex (also referred to as third-generation methods) [16]. The active techniques are such that require supplying additional external energy to the regions of the heat exchange surface, in the form of e.g. vibrations, acoustic or electric field. However, the main disadvantages of the active methods, effectively limiting their application, include high costs, energy intensity and noise as well as safety and reliability considerations [16].

The passive techniques have a considerably wider range of commercial applications. They do not require any extra external energy in order to enhance heat exchange and involve deploying an additional insert, also called a turbulator, inside the tube $[16,17]$. Such a modification of the flow system geometry results in an extended heat exchange surface area and extended duration of liquid presence in the system as well as a reduction of the near-wall layer, leading to an increase in the coefficient of heat transfer from the liquid to the tube wall [17].

The main advantages of the passive methods include their low cost, easy and quick assembly and disassembly of the inserts as well as high reliability. A disadvantage is a considerable drop in the pressure of the liquid in the tube bundle of the evaporator, which occasionally limits the application of these techniques, especially in refrigeration appliances. For instance, spiral wire inserts cause a pressure drop in the range of $30-220 \%$ depending on the wire diameter, spiral pitch and the kind and parameters of the liquid. They enable, however, enhancement of the heat transfer coefficient by $50-280 \%$ $[16,17]$ examined the effect of a spiral spring insert placed in the tubing of a refrigeration appliance on its performance. The investigation comprised inserts with circular, square and triangle cross-sections, of different sizes and pitches. The analyses demonstrated that the highest heating system performance is achieved by means of an insert with a triangular cross-section equal 
to $75.4 \mathrm{~mm}$ and with a ratio between the tube diameter and the insert equal to 10 [17]. The study by Thimmaiah et al. [3] also investigates the effect of turbulators on enhancement of heat exchange inside evaporator tube bundles. Fig. 3 presents schematic of the turbulators used, with an insert of a twisted tape (a and c) and a Ztype turbulator ( $b$ and $d$ ). The authors emphasise that the operation of these turbulators consists in generating vortices in order to reduce the thickness of the near-wall hydrodynamic and thermal layer in the tubing [3].
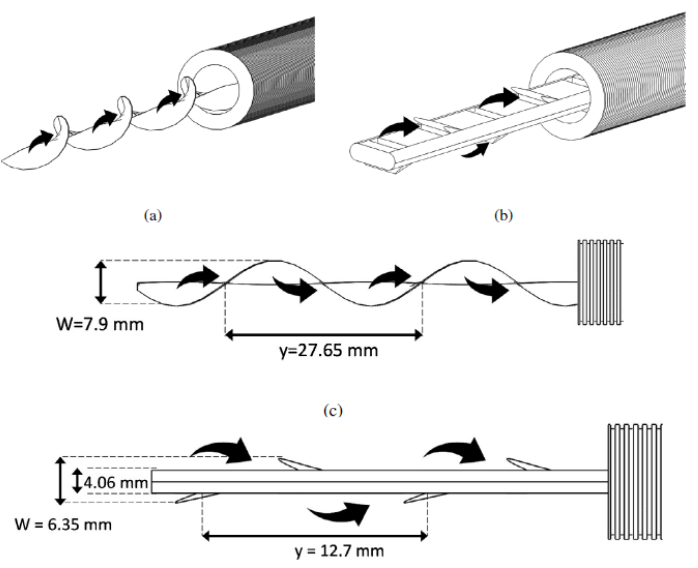

(d)

Fig. 3. Schematic of turbulators: a, c) twisted tape; b, d) Z-type [3].

The investigation demonstrated that inclusion of such inserts in the evaporator tubing results in a significant reduction of heat flow resistance (by $12 \%$ for a twisted tape turbulator and $58 \%$ for a Z-type turbulator relative to the system without such inserts. As already mentioned, the use of turbulators led to a significant increase in flow resistance in the tubing. For twisted tape turbulators and Z-type turbulators, the pressure drop was 2.5 and 14.5 times greater, respectively, than in the case without turbulators. Thus, the use of turbulent flow generators will imply high power demand of the pumps installed, which will in turn cause greater power consumption by the adsorption chiller [3]. However, the inclusion of turbulators in the design caused an improvement in the coefficient of performance (COP) and the specific cooling power (SCP) by $10.5 \%$ and $9 \%$ respectively for twisted tape turbulators and $41 \%$ and $47 \%$ for Z-type turbulators.

Another method of improving thermal parameters of evaporators is by modifying the outside wall of the tubes. In the study by Thimmaiah et al. [3], a rough surface was applied on the fins of the adsorption evaporator tubing (Fig. 6).

Heat transfer coefficient for a tube coated with a layer of copper was 1.4 times greater than the coefficient for the uncoated tubing. The measure applied did not cause any additional loss of pressure and the increase in the COP and SCP was found to be $20 \%$ and $47.6 \%$ respectively relative to the device with uncoated tubes [3].
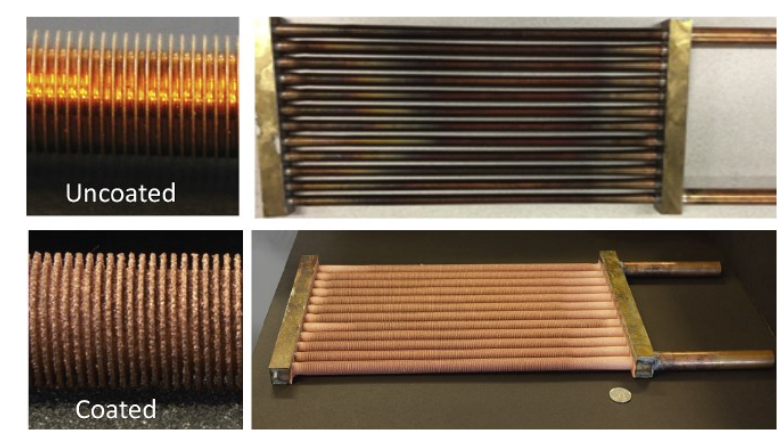

Fig. 4. Uncoated and coated evaporators [3].

\section{Summary}

The review of literature presented in the paper provides grounds for developing selection criteria for the optimal design of evaporators intended for operation in adsorption chillers. Taking account of the values of heat transfer coefficients, falling film evaporators seem to be the optimal design for operation in the conditions of adsorption refrigeration systems. At the same time, attention should also be given to the other options of improving thermal parameters. The application of turbulators and tubes with extended, appropriately designed inside and outside surfaces is another method of reducing heat flow resistance within evaporator tubes.

The paper was supported by Faculty of Energy and Fuels (11.11.210.376)

\section{References}

1. P.C. Thimmaiah, A. Sharafian, W. Huttema, C. Osterman, A. Ismail, A. Dhillon, M. Bahrami, Appl. Th. Eng. 106, pp. 371-380 (2016)

2. P.C. Thimmaiah, A. Sharafian, W. Huttema, C. McCague, M. Bahrami, Appl. En. 171, pp. 256-265 (2016)

3. P.C. Thimmaiah, A. Sharafian, M. Rouhani, W. Huttema, M. Bahrami, Energy 122, pp. 144-158 (2017)

4. R. Z. Wang, L. Wang, J. Wu, Adsorption refrigeration technology: theory and application (John Wiley \& Sons Inc., New York, 2014)

5. K.M. Gutkowski, T.J. Butrymowicz, Tytuł artykułu (in Polish), Chlodnictwo i klimatyzacja, WNT (2015)

6. M. Rubik, Pompy ciepla w systemach geotermii niskotemperaturowej (in Polish) (Multico OW, Warsaw, 2011)

7. W. Li, X.Y. Wu, Z. Luo, S.C. Yao, J.L. Xu, Int. J. Heat and Mass Transfer 54, 9, pp. 1986-1993 (2011)

8. E. Kostowski, Przepływ ciepła (in Polish), Skrypty uczelniane 1652, Silesian University of Technology (1991)

9. R. Zarzycki, Wymiana ciepla i ruch masy (in Polish) (WNT, Warsaw, 2010)

10. Y.A. Cengel, Heat transfer: a practical approach (McGraw-Hill, New York, 2004)

11. T. Fodemski, B. Staniszewski, Badanie modeli wkladow intensyfikujacych wymiane ciepla (in 
Polish), The Bulletin of Institute of Heat Engineering 51, 1-28, Warsaw University of Technology (1978)

12. R. Volmer, J. Eckert, G. Füldner, L. Schnabel, Ren. En. 110, 141-153 (2017)

13. G. Ribatski, A.M Jacobi, Int. J. Ref. 28, 5, pp. 635653 (2005)

14. L. Yang, W. Wang, Int. J. Ref. 34, 1, pp. 303-316 (2011)

15. W. Li, X.Y. Wu, Z. Luo, R.L. Webb, Int. J. Heat and Mass Transfer 54, 13, pp. 2990-2997 (2011)

16. L. Liebenberg, J.P. Meyer, Appl. Th. Eng. 27, 16, pp. 2713-2726 (2007)

17. S. Salari, K. Goudarzi, Th. Sc. and Eng. Prog. 3, pp. 123-132 (2017) 